\title{
Alternative treatment to corticosteroids in steroid sensitive idiopathic nephrotic syndrome
}

\author{
T J Neuhaus, J Fay, M J Dillon, R S Trompeter, T M Barratt
}

\begin{abstract}
A review was undertaken of the use of alternative immunosuppressive treatment in addition to corticosteroids in a cohort of 429 children with steroid sensitive nephrotic syndrome (SSNS) treated between 1980 and 1994. Two hundred and twenty two children $(52 \%)$ received at least one course of alternative treatment, 98 $(23 \%)$ two, and $43(10 \%)$ three. Cyclophosphamide was administered to 196 children (46\%); in 181 it was the first course of alternative treatment and in $104(57 \%)$ of those it was also the last ("final course'). Levamisole was given to 56 children (13\%) and cyclosporin to 53 $(12 \%)$. Fifteen children in whom cyclosporin failed were treated with chlorambucil. A few patients received azathioprine or vincristine. Ten children developed secondary steroid resistance, of whom five progressed to chronic renal failure. Acute complications included reversible renal failure, septicaemia, peritonitis, convulsions, and cerebral thrombosis. There were three deaths. It is concluded that half of the referred children with SSNS were deemed to require at least one course of alternative immunosuppressive treatment, and that side effects of the treatment and complications of SSNS are infrequent but occasionally fatal.

(Arch Dis Child 1994; 71: 522-526)
\end{abstract}

The majority of children with primary nephrotic syndrome have minimal change histology (MCNS) on renal biopsy and respond to corticosteroid treatment. ${ }^{1-3}$ The correlation between MCNS and steroid response is so close that, in the absence of risk factors (that is, hypertension, macroscopic haematuria, raised plasma creatinine concentration, low plasma C3), renal biopsy is usually not necessary as minimal change histology can be assumed. ${ }^{3}$ The annual incidence of steroid sensitive idiopathic nephrotic syndrome (SSNS) in the UK is $1-4$ per 100000 white children. ${ }^{4}{ }^{5}$ There is a marked racial variation in susceptibility with an increased incidence in Asian children ${ }^{45}$ and a tendency to a more severe course in black children. ${ }^{6}$ SSNS has a favourable long term prognosis, but about half the patients experience frequent relapses, ${ }^{7-9}$ which impair the quality of life, particularly when associated with steroid dependence.

A substantial proportion of nephrotic children require further immunosuppressive treatment in addition to corticosteroids. Between
1965 and 1985 this mainly consisted of one or more courses of a cytotoxic agent, either cyclophosphamide ${ }^{1011}$ or chlorambucil. ${ }^{12}$ Since then levamisole ${ }^{13}$ and cyclosporin ${ }^{14-17}$ have been introduced. However, there is neither complete agreement about the stage at which these alternative treatments should be introduced nor about the appropriate protocols. For these reasons the British Association for Paediatric Nephrology and the Research Unit of the Royal College of Physicians recently published a consensus statement on SSNS and defined a series of levels of management. ${ }^{18}$

We therefore undertook a review of all patients with SSNS treated at our hospital between 1980 and 1994 to document their management in terms of the alternative treatments used, the final course of alternative treatment received, and the major complications recorded.

\section{Patients and methods}

PATIENTS

Great Ormond Street Hospital for Children (GOSH) is a tertiary referral centre serving mainly the North Thames region of London which has a population of approximately six million. The Renal Unit at GOSH runs a special clinic for nephrotic children. The majority of these have SSNS and are referred by paediatricians because of frequent relapses or steroid dependence; it is unusual for a child to be referred during the initial episode of nephrotic syndrome unless there are features suggesting steroid resistance. Between 1980 and 1994, 429 patients with SSNS attended GOSH. The observation period ranged from six months to 20 years, including those patients who were initially seen before 1980 . There were 298 males (69\%) and 131 females $(31 \%)$. Most of the children were white, some were Asian, and only a few were black.

Renal biopsies were performed in 155 patients. In $115(74 \%)$, the histology indicated MCNS. In $14(9 \%)$ it showed focal segmental glomerulosclerosis (FSGS); four of these had an initial biopsy showing MCNS. In $13(8 \%)$ it showed focal global glomerulosclerosis (FGS); four of these had an initial biopsy indicative of MCNS. Twelve patients $(8 \%)$ showed diffuse mesangial proliferation; of these one had an initial biopsy finding of MCNS and one of FGS. In 11 patients a precise histological diagnosis was not available.

Since 1980 the clinical data from all patients with SSNS have been collected on a computer database. The following information is 
Table 1 Levels of management of SSNS (modified from $B A P N^{18}$ )

\begin{tabular}{|c|c|c|}
\hline Level & Clinical stage & Treatment \\
\hline 1 & Initial episode & $\begin{array}{l}\text { Prednisolone } 2 \mathrm{mg} / \mathrm{kg} / \text { day until remission, followed } \\
\text { by withdrawal }\end{array}$ \\
\hline 2 & First two relapses & As above \\
\hline 3 & Frequent relapses & $\begin{array}{l}\text { Maintenance prednisolone } 0 \cdot 1-0.5 \mathrm{mg} / \mathrm{kg} / \text { alternate } \\
\text { day for } 3-6 \text { months, then slow withdrawal }\end{array}$ \\
\hline 4 & Relapse on prednisolone $>0.5 \mathrm{mg} / \mathrm{kg} /$ alternate day & Levamisole $2.5 \mathrm{mg} / \mathrm{kg} /$ alternate day for $6-18$ months \\
\hline 5 & $\begin{array}{l}\text { Relapse on prednisolone }>0.5 \mathrm{mg} / \mathrm{kg} / \text { alternate day and steroid } \\
\text { side effects or risk factors or relapse on prednisolone }>1.0 \\
\mathrm{mg} / \mathrm{kg} / \text { alternate day }\end{array}$ & Cyclophosphamide $3 \mathrm{mg} / \mathrm{kg} /$ day for 8 weeks \\
\hline 6 & Relapses after cyclophosphamide & As $2-3$ above \\
\hline 7 & Relapse on prednisolone $>0.5 \mathrm{mg} / \mathrm{kg} /$ alternate day & Cyclosporin $5 \mathrm{mg} / \mathrm{kg} /$ day for at least one year \\
\hline 8 & Relapse on cyclosporin & $\begin{array}{l}\text { Cyclosporin plus maintenance prednisolone } 0 \cdot 1-0 \cdot 5 \\
\mathrm{mg} / \mathrm{kg} / \text { alternate day }\end{array}$ \\
\hline 9 & $\begin{array}{l}\text { Relapse on cyclosporin and maintenance steroids with toxicity } \\
\text { or nephrotoxicity }\end{array}$ & Chlorambucil $0 \cdot 2 \mathrm{mg} / \mathrm{kg} /$ day for 12 weeks \\
\hline 10 & Relapse after chlorambucil & ? \\
\hline
\end{tabular}

BAPN $=$ British Association for Paediatric Nephrology.

recorded: (i) response to steroids, (ii) alternative treatment, (iii) serious complications, (iv) histopathology on renal biopsy if undertaken, and (v) plasma creatinine concentration. In some patients, we have recorded glomerular filtration rate estimated from the plasma clearance of ${ }^{51} \mathrm{Cr}$-EDTA. ${ }^{19}$

The clinical care of these children was shared with both the general practitioner and the referring paediatrician; however, decisions about the introduction of alternative treatment were generally made by GOSH consultants. The children were usually followed up to the age of 16 to 18 years at which stage, if the disease was still active, they were transferred to an adult renal unit.

TREATMENT PROTOCOLS (TABLE 1)

The initial episode and relapses were treated with prednisolone $2 \mathrm{mg} / \mathrm{kg} /$ day with a maximum dose of $75 \mathrm{mg}$ until the urine showed a trace or no protein on a dipstick for three consecutive days after which prednisolone was withdrawn (levels 1 and 2). In frequent relapsers it was tapered slowly to determine each patient's individual prednisolone threshold at which relapse occurred, and maintenance alternate day prednisolone treatment was instituted (level 3). Cyclophosphamide was introduced in 1967 and was given for eight weeks in a dose of $3 \mathrm{mg} / \mathrm{kg} /$ day (ideal weight for height, equivalent to a cumulative dose of $168 \mathrm{mg} / \mathrm{kg}$ per course). Levamisole was used regularly from 1987 in a dose of $2.5 \mathrm{mg} / \mathrm{kg}$ on alternate days for 6-18 months. Cyclosporin was also introduced in 1987. The initial dose was $5 \mathrm{mg} / \mathrm{kg} /$ day and the whole blood trough concentrations (measured by high performance liquid chromatography) were maintained between $50-100 \mu \mathrm{g} / \mathrm{l}$. Patients were maintained on cyclosporin for at least 12 months and some patients received several courses. Chlorambucil was given in a dose of $0.2 \mathrm{mg} / \mathrm{kg} /$ day for 12 weeks (equivalent to a cumulative dose of $16.8 \mathrm{mg} / \mathrm{kg}^{12}$ ).

\section{INDICATIONS FOR ALTERNATIVE TREATMENT} (TABLE 1)

The decision to introduce a treatment alternative to corticosteroids was based on the individual's prednisolone threshold. Levamisole was the first choice if relapses occurred on prednisolone $0.5-1.0 \mathrm{mg} / \mathrm{kg} /$ alternate day (level 4). Cyclophosphamide was introduced when relapses occurred either on prednisolone $>1.0 \mathrm{mg} / \mathrm{kg} /$ alternate day or on $>0.5$ $\mathrm{mg} / \mathrm{kg} /$ alternate day associated with steroid toxicity (marked cushingoid appearance, poor growth, psychological distress, or hypertension) (level 5). If cyclophosphamide failed to induce a long term remission and the patient's prednisolone threshold again reached $>0.5 \mathrm{mg} / \mathrm{kg} /$ alternate day (level 6), some patients who had not previously been given levamisole received it and - if unsuccessful moved on to cyclosporin; the other patients embarked directly upon cyclosporin (level 7). Before 1987 these patients had a second, and rarely, a third course of cyclophosphamide. If cyclosporin failed to maintain remission, alternate day prednisolone was added (level 8). Since 1992 the most refractory patients, that is, those in whom cyclosporin plus prednisolone failed, have been treated with chlorambucil (level 9). Between 1974 and 1987 azathioprine (1-2 $\mathrm{mg} / \mathrm{kg} /$ day for up to six months) and since 1983 intravenous vincristine $\left(1.5 \mathrm{mg} / \mathrm{m}^{2}\right.$, maximum $2 \mathrm{mg}$, weekly for eight weeks) were occasionally used.

\section{DEFINITIONS}

SSNS: remission after four weeks of prednisolone.

Remission: urine with trace or negative protein on a dipstick for three consecutive days and/or urinary albumin/creatinine ratio $<0 \cdot 1 \mathrm{mg} / \mathrm{mg}$. Relapse: two days of $2+$ protein on a dipstick and/or urinary albumin/creatinine ratio $>1 \cdot 0$ $\mathrm{mg} / \mathrm{mg}$.

Final course of alternative treatment: beyond this course the patient did not receive any further alternative treatment, that is, (i) is off treatment, (ii) is maintained on low dose prednisolone $(<0.5 \mathrm{mg} / \mathrm{kg} /$ alternate day), or (iii) remains on long term levamisole or cyclosporin. The database does not differentiate between outcome (i) and (ii).

\section{Results}

LEVELS OF MANAGEMENT

Two hundred and seven (48\%) of the 429 children were treated with prednisolone alone. 
Table 2 Sequence of alternative treatment in 429 children with SSNS

\begin{tabular}{|c|c|c|c|c|c|c|c|}
\hline Course & No (\%) of patients & Levamisole & Cyclophosphamide & Cyclosporin & Chlorambucil & Azathioprine & Vincristine \\
\hline Nil & $207(48)$ & - & - & - & - & - & - \\
\hline $1 \mathrm{st}$ & $222(52)$ & 31 & 181 & 6 & 1 & 3 & - \\
\hline 2nd & $98(23)$ & 18 & 50 & 25 & 1 & 2 & 2 \\
\hline $3 \mathrm{rd}$ & $43(10)$ & 8 & 6 & 14 & 6 & 7 & 2 \\
\hline 4th & $20(5)$ & - & - & 9 & 8 & 3 & - \\
\hline 5th & $4(1)$ & 1 & 1 & - & $\overline{0}$ & - & 2 \\
\hline 6th & $3(1)$ & - & - & - & 2 & - & 1 \\
\hline 7th & $1(0 \cdot 2)$ & - & - & - & - & 1 & - \\
\hline
\end{tabular}

Two hundred and twenty two $(52 \%)$ received one or more courses of alternative treatment; $98(23 \%)$ patients had at least two, $43(10 \%)$ at least three, and $20(5 \%)$ had four or more courses of alternative treatment. The sequence of courses of alternative treatment is shown in table 2 .

\section{Levamisole (level 4)}

Fifty six children (13\%) had levamisole. In 31 it was the first course of alternative treatment and in $16(52 \%)$ of these also the final; 17 had levamisole after a single course of cyclophosphamide and in nine (53\%) of these it was also the final course. Two had a second course of levamisole.

\section{Cyclophosphamide (level 5)}

Cyclophosphamide was given to 196 children (46\% of all patients). In 181 it was the first course of alternative treatment and in 104 $(57 \%)$ of these also the final course. Thirty eight had a second course, 35 in the era before cyclosporin; 21 of the 38 received further alternative treatment, including four patients who had a third course of cyclophosphamide.

\section{Cyclosporin (level 7)}

Fifty three children (12\%) had cyclosporin (data on some of these children have been reported $^{1720}$ ). It was the first course of alternative treatment in six pubertal boys. Forty two of the children had received at least one previous course of cyclophosphamide and five a previous course of levamisole. In $35(66 \%)$ it was the final course of alternative treatment. Two patients were maintained in remission on levamisole after cyclosporin.

In 16 children $(30 \%)$ cyclosporin was deemed to have failed for a number of reasons: secondary steroid and cyclosporin resistance in five, additional steroid dependence with

Table 3 Most common protocols of alternative treatment in SSNS

\begin{tabular}{rllll}
\hline \multirow{2}{*}{$\begin{array}{l}\text { No of } \\
\text { patients }\end{array}$} & \multicolumn{4}{l}{ Course of alternative treatment } \\
\cline { 2 - 5 } & $1 s t$ & 2nd & $3 r d$ & 4 th \\
\hline 104 & Cyclophosphamide & - & - & - \\
17 & Cyclophosphamide & Cyclophosphamide & - & - \\
16 & Levamisole & - & - & - \\
13 & Cyclophosphamide & Cyclosporin & - & - \\
9 & Cyclophosphamide & Levamisole & - & - \\
5 & Levamisole & Cyclophosphamide & - & - \\
5 & Levamisole & Cyclosporin & - & Chlorambucil \\
5 & Cyclophosphamide & Cyclosporin & Cyclosporin & Chlorambucil \\
5 & Cyclophosphamide & Levamisole & - & - \\
4 & Cyclosporin & - & - \\
4 & Cyclophosphamide & Cyclophosphamide & Azathioprine & - \\
4 & Cyclophosphamide & Cyclophosphamide & Cyclosporin & - \\
191 & (86\% of all patients receiving alternative treatment) & \\
\hline
\end{tabular}

steroid toxicity in eight, nephrotoxicity in two, and cerebral venous thrombosis in one. In the two patients in whom renal function deteriorated, cyclosporin was discontinued and renal function recovered, but within a month both developed a steroid resistant relapse. One pubertal boy who had had cyclosporin as his initial alternative treatment subsequently received cyclophosphamide with long term remission.

\section{Chlorambucil (level 9)}

Fifteen children with cyclosporin failure were treated with chlorambucil. Thirteen went into remission, in all of whom the biopsy specimen showed MCNS. After a median observation period of six months (range 1-28), 11 of these are in stable remission off all treatment and two had a further steroid sensitive relapse. Two patients, both with FSGS, remained nephrotic; one of them died from pulmonary oedema while on chlorambucil. Three patients had been on chlorambucil without previous cyclosporin before referral to GOSH.

\section{Other alternative treatment}

Fourteen children were treated with azathioprine and seven with vincristine. However, eight of the children treated with azathioprine and six treated with vincristine remained steroid dependent and therefore received further alternative treatment.

The 10 most commonly employed protocols of alternative treatment in individual patients are shown in table 3.

\section{PROGRESS AND COMPLICATIONS}

Eight $(2 \%)$ patients developed reversible acute renal failure in early relapse due to hypovolaemia with subsequent acute tubular necrosis: three required dialysis. Ten $(2 \%)$ children developed secondary steroid resistance; five of these (four with MCNS, one with FGS) went into remission on chlorambucil. The other five (all FSGS, four white and one Asian) remained steroid resistant and subsequently developed chronic renal failure; three of them had an initial biopsy finding of MCNS, performed when the nephrotic syndrome was still steroid sensitive. The interval between onset of the nephrotic syndrome and steroid resistance ranged from three months to 11.5 years. Three males developed end stage renal failure and required dialysis nine, 12 , and 12.5 years after onset of their nephrotic syndrome. One boy had a plasma creatinine concentration of 
$150 \mu \mathrm{mol} / \mathrm{l}$ at the age of 4 years, and 14 years later it was still $250 \mu \mathrm{mol} / \mathrm{l}$. A girl became resistant to cyclosporin and steroids at the age of 10.5 years, having had SSNS for more than four years. Her glomerular filtration rate dropped within the next six months from 100 to $47 \mathrm{ml} / \mathrm{min} / 1 \cdot 73 \mathrm{~m}^{2}$, she became increasingly nephrotic and had repeated episodes of hypovolaemia. She was started on chlorambucil and was regularly given albumin infusions without any adverse effects. At the age of 11 years, six hours after an albumin infusion, she developed acute pulmonary oedema and died.

Septicaemia and/or peritonitis was seen during relapse in $12(3 \%)$ patients. One patient each suffered from renal and pulmonary venous thrombosis. Cerebral complications were encountered in $12(3 \%)$ patients. One child sustained a cerebral infarct secondary to arterial thrombosis; he is left with a mild hemiparesis. Two patients suffered a venous thrombosis, one girl during massive diuresis after being in remission for two days and one young man (in an adult hospital at the age of 21 years) after vigorous diuretic treatment of oliguria due to unrecognised hypovolaemia. The girl recovered whereas the young man died of subsequent massive cerebral bleeding. Two patients had hypertensive encephalopathy and nine patients (including the two with venous thrombosis) had convulsions.

A third patient died at the age of 10 years after haemorrhage from a duodenal ulcer leading to cardiorespiratory arrest. She had been on prednisolone $1 \mathrm{mg} / \mathrm{kg} /$ day for one week because of a recent relapse.

\section{Discussion}

Most children with SSNS relapse after their initial treatment, but the long term prognosis is good. About half of the children experience frequent relapses and most of these become steroid dependent, a few continuing with active disease in adult life. ${ }^{7-9}$ There are few published data on the overall management or the use of alternative treatment in SSNS. Two studies reported that $50 \%$ and $72 \%$, respectively of children with SSNS had at least one course of cyclophosphamide. 89

This review of the 429 children with SSNS seen at GOSH since 1980 reveals that $50 \%$ of them received at least one course of alternative treatment, $25 \%$ at least two courses, and 5\% had four or more courses. The drug most commonly used was cyclophosphamide which was administered to almost half of all patients; half of these responded to a single course of cyclophosphamide and remained in long term remission, either off treatment or on low dose alternate day prednisolone. This outcome of cyclophosphamide treatment accords with the result of an earlier study from GOSH that showed sustained remission off treatment in $44 \%$ after four years. ${ }^{10}$

Levamisole proved to be effective as the initial form of alternative treatment in half of the patients with milder forms of SSNS, confirming the result of a prospective controlled trial undertaken by the British Association for
Paediatric Nephrology. ${ }^{13}$ In addition, it seems to be worthy of consideration before cyclosporin in patients with continuing relapses after cyclophosphamide.

Cyclosporin was mainly used in patients who remained highly steroid dependent after cyclophosphamide. Our previous experience with cyclosporin in SSNS indicated that up to $40 \%$ of these patients required additional low dose alternate day prednisolone. ${ }^{1720}$ In extending this study our present data show that two thirds of the patients fared well on cyclosporin; however, in one third of them long term cyclosporin eventually failed. The underlying immunological mechanisms for both the more difficult course after cyclosporin withdrawal and the progressive activation of SSNS while on cyclosporin remain unclear.

So far there is no agreement how to proceed in children with SSNS whose disease is not controlled by cyclosporin and who have already had an unsuccessful course of cyclophosphamide. ${ }^{18}$ We have treated these children with chlorambucil. Its optimum therapeutic dose is not established: reported average cumulative doses range from $11 \mathrm{mg} / \mathrm{kg}^{21}$ to $16.9 \mathrm{mg} / \mathrm{kg}$. ${ }^{12}$ In our 'difficult' patients the higher dose was chosen. Chlorambucil induced remission in all children with MCNS.

However, there are two reservations about its use. First, the observation period is still short. Second, the long term side effects of repeated courses of cytotoxic drugs are uncertain. In long term follow up, cyclophosphamide appears to be safe in terms of gonadal function in males and females in a cumulative dose of up to $500 \mathrm{mg} / \mathrm{kg}^{22}{ }^{23}$ For chlorambucil, a dose of less than $10 \mathrm{mg} / \mathrm{kg}$ seems to be safe whereas a dose of more than $18 \mathrm{mg} / \mathrm{kg}$ caused azoospermia in all boys. ${ }^{24}$ The effects of sequential treatment with cyclophosphamide and chlorambucil are not known. More worrying are observations about the development of malignancies in nephrotic children after cytotoxic treatment. So far eight children with leukaemia, including one unpublished case from GOSH 20 years ago, and four with solid tumours have been reported: six after cyclophosphamide, five after chlorambucil, and one after both drugs. ${ }^{825}$ In each child the potential benefit of a cytotoxic agent has to be balanced against its potential long term side effects. In the most refractory patients whose disease is not controlled by cyclosporin and who are at a high risk of complications of the nephrotic syndrome itself, a second course of cytotoxic treatment (that is, chlorambucil) seems to be justified.

Azathioprine and vincristine had no obvious effects on inducing or maintaining remission.

Acute reversible renal failure developed in a few patients early in relapse, due to unrecognised hypovolaemia. Chronic renal failure is a rare outcome in SSNS. It developed many years after onset of the SSNS in only five children, all of whom had become steroid resistant and had FSGS on histology. Three of them had an initial biopsy, performed while still steroid sensitive, indicating MCNS. Whether the latter finding is due to a sampling error, as 
the FSGS often starts in the corticomedullary junction, or represents a real transition from MCNS to FSGS remains unclear. Progression towards FSGS, steroid resistance, and chronic renal failure has not been reported in studies from Finland and the UK, ${ }^{7-9}$ but is not uncommon in black children with MCNS. ${ }^{26-28}$ Five further patients also developed steroid resistance, but subsequently went into remission with normal renal function after a course of chlorambucil. On biopsy these patients showed either MCNS or FGS.

Steroid sensitive nephrotic syndrome carries a significant morbidity. Septicaemia, peritonitis, and thrombosis are well recognised complications. ${ }^{8929-31}$ Our review revealed a high incidence of cerebral complications, including convulsions, hypertensive encephalopathy, and cerebral thrombosis. Sporadic cases of cerebral thrombosis with fatal outcome have been reported. ${ }^{9} 30$

The side effects of treatment were rare, but occasionally fatal. The deaths were related to standard treatment with prednisolone and albumin infusion ${ }^{32}$ in two and inappropriate use of diuretics in one.

These data are based on a selected, referred group of children with SSNS, most of them being frequent relapsers or steroid dependent. It is therefore not appropriate to extrapolate the results to all children presenting with a first episode of SSNS. The data overestimate the need for alternative treatment and the incidence of complications in SSNS.

We conclude that half the children referred with steroid dependent nephrotic syndrome appear to require at least one course of alternative treatment. The stage at which alternative treatment is introduced should be based on each patient's individual steroid threshold. Further alternative treatment is required in half the children who received cyclophosphamide and in a third of those who received cyclosporin. Children poorly controlled on cyclosporin do well on chlorambucil. Progression towards chronic renal failure is rare and occurs only in patients with secondary steroid resistance associated with FSGS. Side effects of the treatment and complications of the SSNS are infrequent, but occasionally fatal.

TJN was supported by the Karl Reiser and Heinrich Paur Fund, Zurich and by the Jubiläumsstiftung Rentenanstalt, Zurich.

1 Glasock RJ, Cohen AH, Bennett CM, Martinez-Maldonado M. Primary glomerular diseases. In: Brenner DG, Rector FC, eds. The kidney. Philadelphia: WB Saunders, 1981: $1351-492$.

2 International Study of Kidney Disease in Children. Nephrotic syndrome in children: prediction of histopathology from clinical and laboratory characteristics at time of diagnosis. Kidney Int 1978; 13: 159-65.

3 International Study of Kidney Disease in Children. The primary nephrotic syndrome in children. Identification of patients with minimal change nephrotic syndrome from initial response to prednisone. $\mathcal{J}$ Pediatr 1981; 98: 561-4.
4 Sharples PM, Poulton J, White RHR. Steroid responsive nephrotic syndrome is more common in Asians. Arch Dis Child 1985; 60: 1014-7.

5 Feehally J, Kendell NP, Swift PGF, Walls J. High incidence of minimal change nephrotic syndrome in Asians. Arch Dis Child 1985; 60: 1018-20.

6 Schlesinger ER, Sultz HA, Mosher WE, Feldman JG. The nephrotic syndrome. Its incidence and implications for the community. Am $f$ Dis Child 1968; 116: 623-32. 7 Koskimies O, Vilska J, Rapola J, Hallman N. Long-term outcome of primary nephrotic syndrome. Arch Dis Child 1982; 57: 544-8.

8 Trompeter RS, Lloyd BW, Hicks J, White RHR. Long-term outcome for children with minimal-change nephrotic syndrome. Lancet 1985; i: 368-70.

9 Lewis MA, Baildom EM, Davis N, Houston IB, Postlethwaite RJ. Nephrotic syndrome: from toddlers to twenties. Lancet 1989; i: 255-9.

10 Barratt TM, Bercowsky A, Osofsky SG, Soothill JF. Cyclophosphamide treatment in steroid sensitive nephrotic syndrome of childhood. Lancet 1975; i: 55-8.

11 nephrotic syndrome of childhood. Lancet in Children. Prospective, controlled trial of cyclophosphamide therapy in children with the nephrotic syndrome. Lancet 1974; ii: in child $423-7$.

12 Grupe WE, Makker SP, Ingelfinger JR. Chlorambucil treatment of frequently relapsing nephrotic syndrome. $N$ Eng f Med 1976; 295: 746-9.

13 British Association for Paediatric Nephrology. Levamisole for corticosteroid dependent nephrotic syndrome in childhood. Lancet 1991; 337: 1555-7.

14 Brodehl J, Brandis M, Helmchen U, et al. Cyclosporin A treatment in children with minimal change nephrotic syndrome and focal segmental glomerulosclerosis. Kyndrome and focal segmental gloment

15 Tejani A, Suthanthiran M, Pomrantz A. A randomised controlled trial of low dose prednisolone and cyclosporin versus high dose prednisolone in nephrotic syndrome of childhood. Nephron 1991; 59: 96-9.

16 Niaudet $P$, Broyer $M$, Habib R. Treatment of idiopathic nephrotic syndrome with cyclosporin $\mathrm{A}$ in children. Clin Nephrol 1991; 35 (suppl 1): 31-6.

17 Hulton SA, Neuhaus TJ, Dillon MJ, Barratt TM. Long-term cyclosporin A treatment of minimal-change nephrotic syndrome of childhood. Pediatr Nephrol 1994; 8: 401-3.

18 British Association for Paediatric Nephrology. Consensus statement on management and audit potential for steroid responsive nephrotic syndrome. Arch Dis Child 1994; 70: responsive.

19 Chantler C, Barratt TM. Estimation of glomerular filtration rate from plasma clearance of 51 chromium edetic acid. Arch Dis Child 1972; 47: 613-7.

20 Hulton SA, Jadresic J, Shah V, Trompeter RS, Dillon MJ, Barratt TM. Effect of cyclosporin A on glomerular filtration rate in children with minimal change nephrotic syndrome. Pediatr Nephrol 1994; 8: 404-7.

21 Balurate HJ, Hiner L, Gruskin AB. Chlorambucil dosage in frequently relapsing nephrotic syndrome: a controlled trial. $\mathcal{F}$ Pediatr 1978; 92: 295-8.

22 Bogdanovic R, Banicevic M, Cvoric A. Testicular function following cyclophosphamide treatment for childhood nephrotic syndrome: long-term follow-up study. Pediatr Nephrol 1990; 4: 451-4.

23 Bogdanovic R, Banicevic M, Cvoric A. Pituitary-gonada function in women following cyclophosphamide treatment for childhood nephrotic syndrome: long-term follow-up study. Pediatr Nephrol 1990; 4: 455-8.

24 Callis L, Nieto J, Vila A, Rende J. Chlorambucil treatmen in minimal-lesion nephrotic syndrome: a reappraisal of it gonadal toxicity. F Pediatr 1980; 97: 653-6.

25 Elzouki AY, Al-Nassar K, Al-Ali M, Malik G, Elsharie F, Jaiswal OP. Sister chromatid exchange analysis in monitoring chlorambucil therapy in primary nephrotic syndrome of childhood. Pediatr Nephrol 1991; 5: 59-61.

26 Tejani A. Morphological transition in minimal change nephrotic syndrome. Nephron 1985; 39: 157-9.

27 Ingulli E, Gonzalez R, Rajpoot D, Tejani A. Nephrotic Ingulli E, Gonzalez R, Rajpoot D, Tejani A. Nephrotic syndrome: from toddlers to twenties. Lancet 1989 ; i: 674 . minimal-change disease. Lancet 1989; i: 1199-200.

minimal-change disease. Lancet 1989; i: 1199-200.
Gorensek MJ, Lebel MH, Nelson JD. Peritonitis in children with nephrotic syndrome. Pediatrics 1988; 81: 849-56.

30 Mehls O, Andrassy K, Koderisch J, Herzog U, Ritz E. Hemostasis and thromboembolism in children with nephrotic syndrome: differences from adults. $\mathcal{f}$ Pediat 1987; 110: 862-7.

31 Hoyer PF, Gonda S, Barthels M, Krohn HP, Brodehl J Thromboembolic complications in children with nephrotic syndrome: risk and incidence. Acta Paediatr Scand 1986; 75: 804-10.

32 Haws RM, Baum M. Efficacy of albumin and diuretic therapy in children with nephrotic syndrome. Pediatrics 1993; 91: 1142-6. 